\title{
Extracorporeal membrane oxygenation in patients with COVID-19: 1-year experience
}

\author{
Koray Durak $^{1 \# \wedge}$, Rashad Zayat ${ }^{1 \#}$, Oliver Grottke ${ }^{2}$, Michael Dreher ${ }^{3}$, Rüdiger Autschbach ${ }^{1}$, Gernot Marx $^{4}$, \\ Nikolaus Marx ${ }^{5}$, Jan Spillner ${ }^{1}$, Sebastian Kalverkamp ${ }^{1 *}$, Alexander Kersten ${ }^{5 *}$ \\ ${ }^{1}$ Department of Thoracic and Cardiovascular Surgery, RWTH University Hospital Aachen, Aachen, Germany; ${ }^{2}$ Department of Anesthesiology, \\ RWTH University Hospital Aachen, Aachen, Germany; ${ }^{3}$ Department of Pneumology and Intensive Care Medicine, RWTH University Hospital \\ Aachen, Aachen, Germany; ${ }^{4}$ Department of Intensive Care and Intermediate Care Medicine, RWTH University Hospital Aachen, Aachen, Germany; \\ ${ }^{5}$ Department of Cardiology, Angiology, and Intensive Care, RWTH University Hospital Aachen, Aachen, Germany \\ Contributions: (I) Conception and design: M Dreher, R Autschbach, G Marx, N Marx, J Spillner, S Kalverkamp, A Kersten; (II) Administrative \\ support: R Zayat, R Autschbach, J Spillner, S Kalverkamp; (III) Provision of study materials or patients: M Dreher, G Marx, N Marx; (IV) Collection \\ and assembly of data: K Durak, R Zayat, A Kersten; (V) Data analysis and interpretation: K Durak, R Zayat, A Kersten; (VI) Manuscript writing: All \\ authors; (VII) Final approval of manuscript: All authors. \\ \#These authors contributed equally to this work. \\ *These authors contributed equally to this work. \\ Correspondence to: Koray Durak. Paulwelsstraße 30, 52074 Aachen, Germany. Email: koray.durak@outlook.de.
}

Background: Extracorporeal membrane oxygenation (ECMO) in patients with coronavirus disease 2019 (COVID-19) showed reasonable outcomes. However, recent studies indicated a negative trend and analysis is needed.

Methods: Baseline characteristics, laboratory parameters, and outcomes of ECMO-supported patients with COVID-19 were analyzed in a retrospective single-center study. We included hospital admissions until February 28, 2021; patients were followed until discharge/death. Eventually, we compared data between patients hospitalized before and after September 1, 2020.

Results: Median age of patients treated with ECMO ( $n=39)$ was 56 years; most patients were males $(n=28$, $72 \%$ ). Median mechanical ventilation time (prior to ECMO) was 6 days, while the median ECMO duration was 19 days. Overall survival rate was $41 \%$. In the sub-analysis, survival until discharge in the first and second epidemic waves was $53 \%(n=19)$ and 30\% ( $n=20)$, respectively $(P=0.2)$. At baseline, compared with patients of the first wave, those of the second wave had higher median body mass index $\left(28.2 v s .31 .1 \mathrm{~kg} / \mathrm{m}^{2}\right.$, respectively, $\mathrm{P}=0.02)$, bicarbonate (27 vs. $31.8 \mathrm{mmol} / \mathrm{L}$, respectively, $\mathrm{P}=0.033)$, plasma free hemoglobin (36 vs. $58 \mathrm{mg} / \mathrm{L}$, respectively, $\mathrm{P}=0.013$ ), alanine aminotransferase (33 vs. $52 \mathrm{U} / \mathrm{L}$, respectively, $\mathrm{P}=0.018$ ), and $\mathrm{pH}$ (7.29 vs. 7.42, respectively, $\mathrm{P}=0.005)$, lower rate of pulmonary hypertension $(32 \% v s .0 \%$, respectively, $\mathrm{P}=0.008$ ), lower positive end-expiratory pressure (14 vs. $12 \mathrm{cmH}_{2} \mathrm{O}$, respectively, $\left.\mathrm{P}=0.04\right)$, longer median ECMO duration (16 vs. 24.5 days, respectively, $\mathrm{P}=0.074)$, and more frequent major bleeding events ( $42 \%$ vs. $80 \%$, respectively, $\mathrm{P}=0.022$ ).

Conclusions: ECMO-supported patients with COVID-19 had an overall survival rate of $41 \%$. Similar to international registries, we observed less favorable outcomes during the second wave. Further research is needed to confirm this signal and find predictors for mortality.

Keywords: Extracorporeal membrane oxygenation (ECMO); extracorporeal life support (ECLS); coronavirus disease 2019 (COVID-19)

\footnotetext{
^ ORCID: 0000-0003-1951-9251.
} 
Submitted Jun 12, 2021. Accepted for publication Aug 19, 2021.

doi: $10.21037 /$ jtd-21-971

View this article at: https://dx.doi.org/10.21037/jtd-21-971

\section{Introduction}

The rapid spread of coronavirus disease 2019 (COVID-19) dramatically affected international healthcare delivery with a high proportion of patients requiring respiratory support and intensive care unit (ICU) admission $(1,2)$. Several studies reported high ICU mortality rates ranging from $31 \%$ to $42 \%$ (3). Acute respiratory distress syndrome (ARDS) is a common complication which contributed to the high mortality rates reported in previous studies (4). In some patients with severe ARDS or acute respiratory failure, conventional therapies (e.g., MV) are not successful and extracorporeal membrane oxygenation (ECMO) therapy is indicated $(5,6)$. Even though ECMO is a complex therapy provided only by specialist centers with sufficient resources (7), the Extracorporeal Life Support Organization (ELSO) guidelines recommended its use in carefully selected patients (8). This recommendation was supported by an early analysis including 1,035 ECMOsupported patients with COVID-19 that showed reasonable results with a 90 -day mortality of $37.4 \%$ (9). Furthermore, a meta-analysis including nearly 1900 patients reported a mortality rate of $37.1 \%$ (10). These findings were comparable to mortality rates in non-COVID-19 related ARDS patients (11).

A second wave of critically ill patients with COVID-19 arose in Germany after September 2020; however, literature on ECMO outcomes since the second pandemic wave is limited. Meanwhile, the updated guidelines published by the ELSO stated that overall mortality of patients with COVID-19 receiving ECMO may be increasing (12). Thus, there is a need for new analysis of ECMO therapy data, including admissions of patients with COVID-19 during the second epidemic wave.

Hence, we conducted a retrospective, single-center study to evaluate the characteristics, physiologic parameters, and outcomes of patients with COVID-19 who received ECMO therapy. The aim of this study was to: (I) describe our experience of ECMO therapy in patients with COVID-19 after 1 year of practice; and (II) compare the baseline characteristics and outcomes between patients of the first and second epidemic waves.

We present the following article in accordance with the STROBE reporting checklist (available at https://dx.doi. org/10.21037/jtd-21-971).

\section{Methods}

\section{Patients and diagnosis of COVID-19}

This single-center, retrospective study included all patients aged $\geq 18$ years admitted to the hospital between March 1, 2020 and February 28, 2021, who were diagnosed with COVID-19 according to the World Health Organization interim guidance (6) and developed severe COVID-19 disease with ARDS requiring support through ECMO. ARDS was determined according to the 2011 Berlin Definition of the European Society of Intensive Care Medicine (13). Regarding ECMO types, we included patients receiving veno-venous (VV) and veno-arterial (VA) configurations.

\section{Data collection}

We collected data including demographics, medical history, time course of laboratory and MV parameters, and ECMO settings throughout the entire duration of hospital stay. We also gathered data regarding the amount of packed red blood cells (PRBC) and albumin units utilized during ECMO therapy. Of note, PRBC units contained 200-300 mL. Data were collected at two time points (September 1, 2020 and March 21, 2021). Patients admitted to the hospital after September 1, 2020 were assigned to the second epidemic wave.

Screening for the occurrence of complications was conducted daily according to our standard clinical protocol. Laboratory analyses were routinely performed daily; blood gas analyses were performed at intervals of $1-2 \mathrm{~h}$. The study was conducted in accordance with the Declaration of Helsinki (as revised in 2013). The study was approved by the local ethics board of RWTH Uniklinik Aachen (No. 20085) and individual consent for this retrospective analysis was waived.

\section{ECMO settings}

Critically ill patients with COVID-19 were considered for ECMO treatment based on the following criteria: 
(I) Presence of indications for ECMO as suggested by the ELSO guidelines (14); and (II) Failure of all other treatments options (i.e., lung protective invasive $\mathrm{MV}$, prone positioning, neuro-muscular blockade, and inhaled nitric oxide [iNO] rescue therapy). The decision on initiation of ECMO treatment was determined by consensus of our (mobile) ECMO-team consisting of internal medicine intensivists, cardiothoracic surgeons, and pneumologists.

The ECMO devices used in our ICU were iLA ACTIVVE XLUNG kits (XENIOS, Heilbronn, Germany) and Cardiohelp HLS systems Version 7.0 (Maquet Cardiopulmonary GmbH, Rastatt, Germany). Data on ECMO settings, utilization (i.e., VV or VA), cannulation sites, utilization switch (i.e., from VV to VA or veno-venous arterial) were recorded. Our standard approach for the treatment of isolated respiratory failure was VV ECMO.

\section{Anticoagulation regime}

The following hemostatic parameters were measured daily: activated partial thromboplastin time (aPTT), international normalized ratio (INR), platelet count, fibrinogen, antithrombin, D-dimer, and activated clotting time (ACT). The aPTT and ACT were measured thrice and four times daily, respectively, as control for adequate coagulation and not as target values. In addition, factor XIII was measured thrice weekly. The following protocol was used in all patients of the study. In the absence of other relevant indications for a higher anticoagulation target (e.g., atrial fibrillation or mechanical heart valve prosthesis), we primarily administered $400 \mathrm{IE} / \mathrm{h}$ of unfractionated heparin. In the absence of bleeding complications at the beginning, anticoagulation was tapered stepwise to achieve an aPTT of 40-60 seconds and we tolerated an ACT $\leq 180$ s. If necessary, the dose of unfractionated heparin was reduced or its administration paused. Other target values were: platelet count $>50 \mathrm{G} / \mathrm{L}$; fibrinogen $>150 \mathrm{mg} / \mathrm{dL}$; and INR $<1.5$. In case of bleeding, we adjusted the target values using fresh frozen plasma or PRBC. We aimed for an ACT $<160 \mathrm{~s}$, normalized the INR, and raised the platelet count to $\geq 80 \mathrm{G} / \mathrm{L}$ and fibrinogen to $>200 \mathrm{mg} / \mathrm{dL}$.

\section{Bleeding complications}

All bleeding events that led to the use of two or more units of whole blood or red cells and/or a fall in hemoglobin by $>1.24 \mathrm{mmol} / \mathrm{L}$ were identified as major according to the definition established by the International Society on
Thrombosis and Haemostasis (ISTH) (15). We selected the ISTH classification because of its applicability to patients treated with anticoagulants and ECMO being a nonsurgical treatment.

Transfusion of PRBC was very frequent, aiming to maintain a hemoglobin value of $9 \mathrm{~g} / \mathrm{dL}$ in $\mathrm{VV}$ ECMO. However, as our main ECMO target aside from ultraprotective ventilation was sufficient oxygen delivery, we calculated the ratio of oxygen delivery $\left(\mathrm{Do}_{2}\right)$ to oxygen consumption $\left(\mathrm{VO}_{2}\right)$ several times daily and aimed for a ratio of $\geq 3: 1$; and ideally of $\geq 4: 1$ with ECMO blood flow as low as possible. Thus, in some patients, a transfusion of PRBC was required due to low Do2:Vo2 ratios, although the level of hemoglobin was approximately $10 \mathrm{~g} / \mathrm{dL}$.

\section{Statistical analysis}

Categorical variables are presented as absolute numbers and percentages. Continuous variables were tested for normal distribution using the Kolmogorov-Smirnov test and presented as the median and interquartile range (IQR). For comparison between patients from the first and second waves, univariate analyses were performed using the MannWhitney U test for continuous variables and Fisher's exact test for categorical variables. Analyses of laboratory parameters at three-time points were conducted using Friedman's nonparametric test with Dunn's correction for repeated measurement.

All statistical comparisons were two-sided. P-values $<0.05$ denoted statistically significant differences. Statistical analysis was performed using the SPSS Version 26.0 (IBM Corp., Armonk, NY, USA) software. Time courses of laboratory parameters were created using the GraphPad Prism Version 8.0 (GraphPad Software, San Diego, CA, USA) software. Kaplan-Meier survival estimates, including visualization, were obtained using the open-source Jamovi Version 1.2.22.0 software.

\section{Results}

\section{Baseline characteristics}

During the study period, a total of 39 patients were treated with ECMO at our university hospital. The proportion of patients transferred from other referring hospitals was $85 \%$, and mobile ECMO support (from our retrieval team) was provided to $23 \%$ of the patients (Table 1). VA ECMO was indicated in one patient due to severe right ventricular 
Table 1 Baseline characteristics

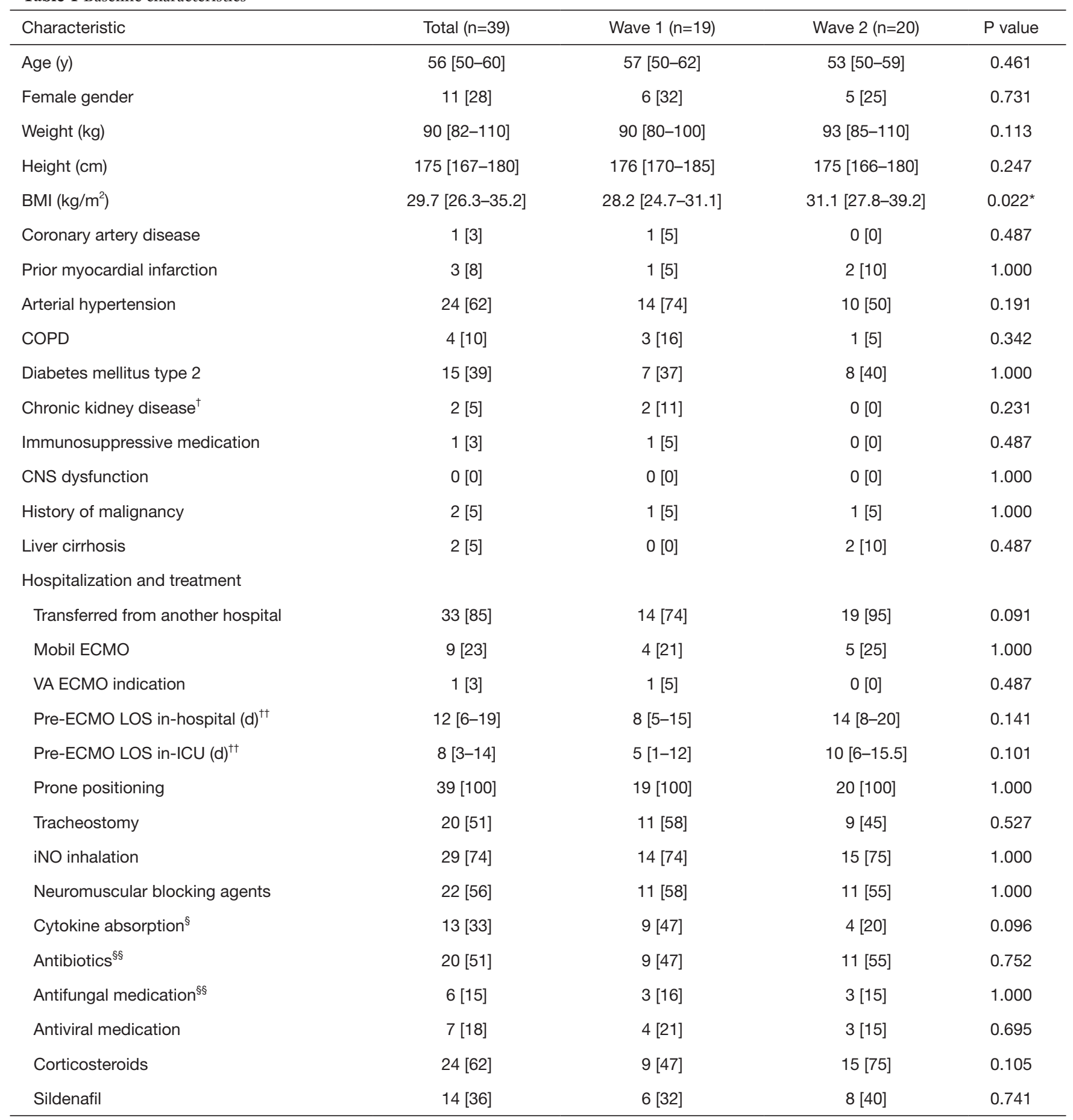

Table 1 (continued) 
Table 1 (continued)

\begin{tabular}{|c|c|c|c|c|}
\hline Characteristic & Total $(\mathrm{n}=39)$ & Wave $1(n=19)$ & Wave $2(n=20)$ & $P$ value \\
\hline Secondary hepatopathy & 5 [13] & $4[21]$ & $1[5]$ & 0.182 \\
\hline Pulmonary hypertension & $6[15]$ & $6[32]$ & $0[0]$ & $0.008^{*}$ \\
\hline Hypercapnia at ECMO-initiation & $7[18]$ & $5[26]$ & $2[10]$ & 0.235 \\
\hline Prior SOFA score & $10[8-11]$ & $11[7-13]$ & $10[8-11]$ & 0.588 \\
\hline Prior RESP Score & $0[-1$ to 2$]$ & $0[-3$ to 2$]$ & $0[-1$ to 2$]$ & 0.214 \\
\hline \multicolumn{5}{|l|}{ Mechanical ventilation } \\
\hline Prior MV time $(\mathrm{d})^{\dagger \dagger}$ & $6[3-15]$ & 4 [3-15] & $9[3-15]$ & 0.708 \\
\hline $\mathrm{pO}_{2}: \mathrm{FiO}_{2}$ (ratio) & $1.04[0.82-1.29]$ & $1.06[0.71-1.36]$ & $1.02[0.83-1.22]$ & 0.923 \\
\hline Pinsp (mbar) & 27 [24-30] & 28 [25-30] & 25.5 [23-28] & 0.204 \\
\hline PEEP $\left(\mathrm{cmH}_{2} \mathrm{O}\right)$ & $12[10-14]$ & $14[10-15]$ & $12[10-13.5]$ & $0.044^{*}$ \\
\hline
\end{tabular}

Continuous variables are presented as median and interquartile range [IQR] or $\mathrm{n}(\%)$. *, $\mathrm{P}$ values under 0.05 are considered as significant and tagged with an asterisk; ${ }^{\dagger}$, Including all patients with a MDRD-GFR $<60 \mathrm{~mL} / \mathrm{min} ;{ }^{\dagger \dagger}$, Including time in the previous hospital; ${ }^{\S}$, Started before ECMO or incorporated in the ECMO circuit; ${ }^{\S}$, Medication due to superinfection. BMI, body mass index kg/m2; CNS, Central nervous system; COPD, chronic obstructive pulmonary disease; ECMO, extracorporeal membrane oxygenation; ICU, intensive care unit; iNO, inhaled nitric oxide; LOS, length of stay; MV, Mechanical ventilation; PEEP, Positive end-expiratory pressure; Pinsp, Peak inspiratory pressure; RESP, The Respiratory Extracorporeal Membrane Oxygenation Survival Prediction; SOFA, Sequential Organ Failure Assessment Score; VA, veno-arterial.

decompensation after pulmonary embolism in both lungs; all other patients received VV ECMO. We reported an overall median age of 56 (IQR: 50-60) years, body mass index (BMI) of 29.7 (IQR: 26.3-35.2) kg/m², and (preECMO) hospitalization time of 12 (IQR: 6-19) days. The most frequent comorbidities were arterial hypertension and diabetes mellitus type 2 (62\% and $39 \%$, respectively). Several treatments were performed before and/or during implantation of ECMO: prone positioning (100\%), iNO (74\%), corticosteroids (62\%), and neuromuscular blocking agents (NMB) (56\%). The most frequent complications prior to ECMO were pneumomediastinum, hypercapnia, pulmonary hypertension, and secondary hepatopathy in $23 \%, 18 \%, 15 \%$, and $13 \%$ of the patients, respectively. We reported a median Respiratory ECMO Survival Prediction (RESP) of 0 (IQR: -1-2) and Sequential Organ Failure Assessment (SOFA) of 10 (IQR: 8-11). The median (preECMO) MV time was 6 (IQR: $3-15$ ) days, and $49 \%$ of the patients received $M V$ for $>7$ days.
We performed a comparison of the baseline characteristics of patients between the first $(n=19)$ and second $(n=20)$ waves. Compared with patients of the first wave, those of the second wave had significantly higher median BMI [28.2 (IQR: 24.7-31.1) vs. 31.1 (IQR: 27.8$39.2) \mathrm{kg} / \mathrm{m}^{2}$, respectively, $\mathrm{P}=0.022$ ], significantly lower median positive end-expiratory pressure (PEEP) [14 (IQR: 10-15) vs. 12 (IQR 10-13.5) $\mathrm{cmH}_{2} \mathrm{O}$, respectively, $\mathrm{P}=0.044$ ], and a significantly lower rate of (pre-ECMO) pulmonary hypertension ( $32 \%$ vs. $0 \%$, respectively, $\mathrm{P}=0.008)$. The median age of patients was 57 (IQR: 50-62) and 53 (IQR 50-59) years, respectively $(\mathrm{P}=0.461)$. The median (preECMO) duration of hospitalization was 8 (IQR: 5-15) and 14 (IQR: 8-20) days, respectively $(\mathrm{P}=0.141)$. Regarding treatments before and/or during initiation of ECMO, patients of the second wave received less CytoSorb (cytokine absorption) therapy (47\% vs. $20 \%$, respectively, $\mathrm{P}=0.096$ ) and more corticosteroids ( $47 \%$ vs. $75 \%$, respectively, $\mathrm{P}=0.105)$. Patients of the second wave showed a higher 
median (pre-ECMO) MV time [4 (IQR: 3-15) vs. 9 (IQR: 3-15) days, respectively, $\mathrm{P}=0.708]$. The median RESP scores were similar in both groups [0 (IQR: $-3-2)$ vs. 0 (IQR: $-1-2)$, respectively, $\mathrm{P}=0.214]$. Further details are presented in Table 1.

\section{Laboratory parameters}

The 23 different laboratory measurements are presented in Table 2. In the total study sample $(\mathrm{n}=39)$, we reported a median partial pressure of oxygen $\left(\mathrm{pO}_{2}\right)$ of 68 (IQR: 5476) $\mathrm{mmHg}$, partial pressure of carbon dioxide $\left(\mathrm{pCO}_{2}\right)$ of 65 (IQR: 51-77) mmHg, C-reactive protein of 211 (IQR: 100 287) $\mathrm{mg} / \mathrm{L}, \mathrm{D}$-dimer of 4,547 (IQR: $1,876-11,006) \mu \mathrm{g} / \mathrm{dL}$, and fibrinogen of 466 (IQR: $409-717$ ) $\mathrm{mg} / \mathrm{dL}$ prior to implantation of ECMO.

We compared the laboratory parameters of patients between the first $(n=19)$ and second $(n=20)$ waves at three different time points and found multiple statistically significant differences (Table 2, Figure 1, Table S1). Before implantation of ECMO: patients of the second wave had significantly higher $\mathrm{pH}$ (median: 7.29 vs. 7.42, respectively, $\mathrm{P}=0.005$ ), bicarbonate (median: 27 vs. $31.8 \mathrm{mmol} / \mathrm{L}$, respectively, $\mathrm{P}=0.033)$, plasma free hemoglobin $(\mathrm{pfHb})$ (median: 36 vs. $58 \mathrm{mg} / \mathrm{L}$, respectively, $\mathrm{P}=0.013$ ), and alanine aminotransferase (ALT) (median: 33 vs. $52 \mathrm{U} / \mathrm{L}$, respectively, $\mathrm{P}=0.018$ ) levels. After implantation of ECMO $(24 \mathrm{~h})$ : patients of the second wave showed significantly higher aPTT (median: 34 vs. $44 \mathrm{~s}$, respectively, $\mathrm{P}=0.038$ ) and antithrombin III (median: $48 \%$ vs. $71 \%$, respectively, $\mathrm{P}=0.008$ ) levels, and significantly lower creatinine (median: 1.5 vs. $1 \mathrm{mg} / \mathrm{dL}$, respectively, $\mathrm{P}=0.033$ ) levels. Before explantation of ECMO: patients of the second wave showed significantly higher C-reactive protein (median: $118 \mathrm{vs}$. $251 \mathrm{mg} / \mathrm{L}$, respectively, $\mathrm{P}=0.006)$ and significantly lower blood urea nitrogen (median: 98 vs. 70 s, respectively, $\mathrm{P}=0.004)$ levels.

\section{Outcomes}

Outcomes, complications, and administration of blood products are presented in Table 3. Of the 39 patients, $41 \%$ were successfully weaned from ECMO therapy and survived until discharge. A total of 23 patients expired, and there were no patients who remained hospitalized. The median duration of ECMO was 19 (IQR: 11-29) days. In the one patient who received VA ECMO, we reported recovery of right ventricular function and successful weaning from
ECMO after 27 days. Thromboembolic events (TEE) occurred in $36 \%$ of the patients, and pulmonary artery embolism was the most frequent (21\%). Major bleeding events (MBE) occurred in $62 \%$ of the patients; the most frequent locations were endobronchial and mucosal bleedings in the upper respiratory tract (23\% each). The incidence of acute kidney failure was $72 \%$; renal replacement therapy was applied to all cases. The median amount of PRBC used during ECMO therapy was 1.5 (IQR: $0.8-2.0)$ units per day.

We also compared the outcomes of patients of the first $(n=19)$ and second $(n=20)$ waves. Compared with patients of the first wave, those of the second wave had a significantly higher rate of $\mathrm{MBE}(42 \%$ vs. $80 \%$, respectively, $\mathrm{P}=0.022$ ), lower survival until discharge ( $53 \%$ vs. $30 \%$, respectively, $\mathrm{P}=0.200$ ) and longer duration of ECMO [16 (IQR: 11-24) vs. 24.5 (IQR: 15.3-33) days, respectively, $\mathrm{P}=0.074$ ]. The hazard ratio for death within 90 days after initiation of ECMO in the second wave, compared with the first wave, was 1.57 (95\% CI: 0.68-3.65, $\mathrm{P}=0.284$ ) (Figure 2). Patients of the second wave exhibited a lower incidence of thromboembolic events ( $42 \%$ vs. $30 \%, \mathrm{P}=0.514)$. Acute kidney failure occurred in $68 \%$ and $75 \%$ of the patients, respectively, $(\mathrm{P}=0.447)$. Despite the higher rate of bleeding events, the median amount of PRBC administered was lower in the second wave [1.5 (IQR: 0.8-2.0) vs. 1 (IQR: 0.7-1.8) units per day, respectively, $\mathrm{P}=0.285]$. Further details are presented in Table 3.

\section{Discussion}

Since the beginning of 2020, a large number of patients with COVID-19 received support with ECMO at our center; the majority were transferred from other hospitals. Most of our patients received NMB agents, antibiotics, steroids, and iNO prior to initiation of ECMO. A high proportion of our patients remained for $>1$ week in the ICU and $49 \%$ received $M V$ for $>7$ days. The rate of survival to discharge was $41 \%$ in total. However, the number of ECMO non survivors were higher during the second wave, in line with the higher mortality reported during the second wave globally. Similar trends were observed in other centers using ECMO during the second wave, irrespective of the burden of the pandemic. Survival to discharge was $53 \%$ and $30 \%$ in the first and second wave, respectively, $(\mathrm{P}=0.200)$; even though the median RESP in both groups was 33-57\%. The difference in survival was statistically non-significant in our study, but the impact on clinical practice is highly 
Table 2 Laboratory parameters before ECMO-initiation

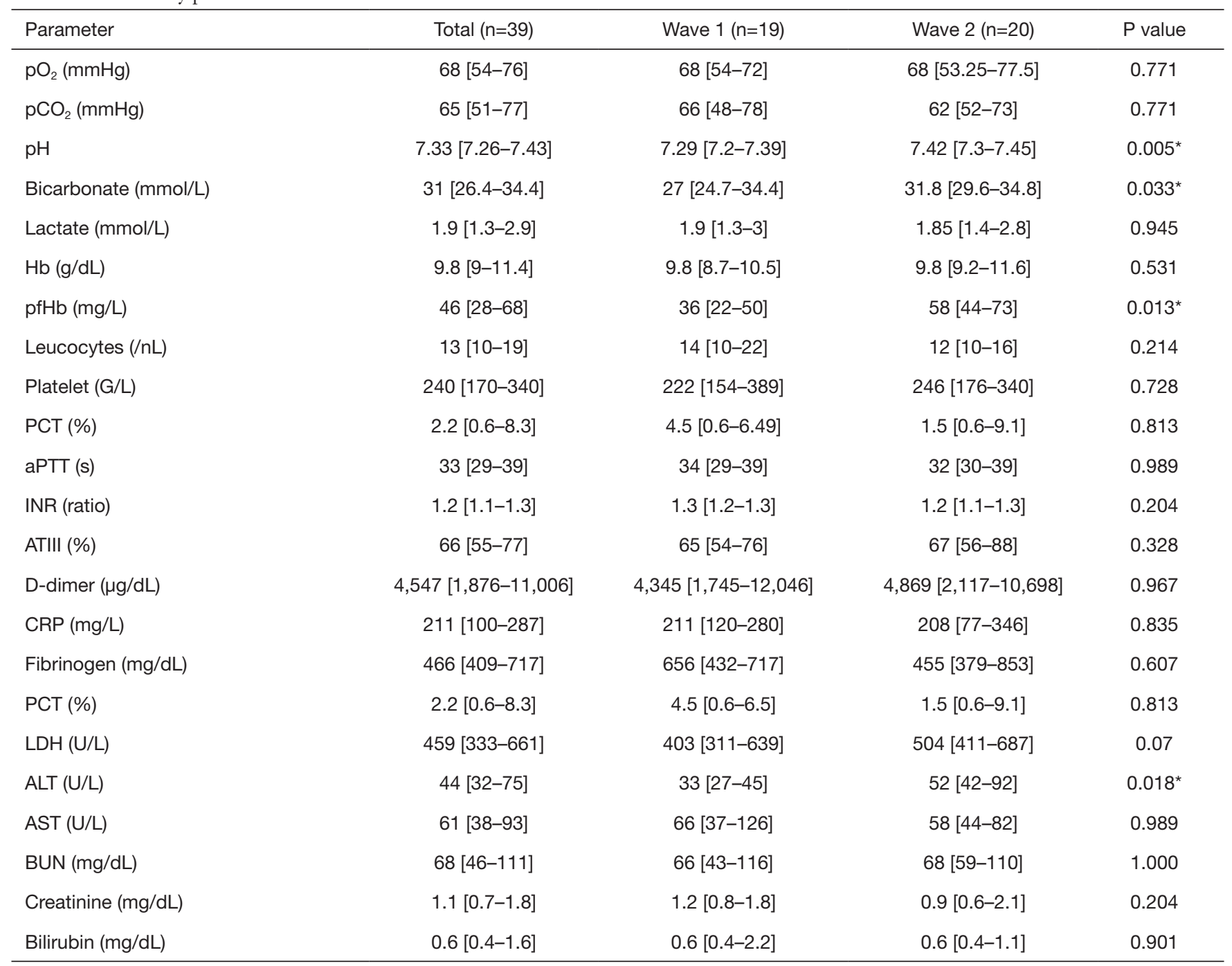

Continuous variables are presented as median and interquartile range [IQR] or $\mathrm{n}(\%) .{ }^{*}, \mathrm{P}$ values under 0.05 are considered as significant and tagged with an asterisk. All parameters were measured 1-6 hours before ECMO-initiation. ALT, alanine transaminase; AST, aspartate transaminase; ATIII, Antithrombin III, aPTT, partial thromboplastin time; BUN, blood urea nitrogen; CRP, C-reactive protein; ECMO, extracorporeal membrane oxygenation; Hb, Hemoglobin; LDH, lactate dehydrogenase; PCT, procalcitonin; pfHb, plasma-free hemoglobin; WBC, white blood cells.

relevant since this negative trend has been reported by the ELSO registry (16). Broman and colleagues reported that successful weaning was accomplished in $58 \%(841$ of 1,442$)$ of patients in the first wave, compared with $47 \%$ (718 of $1,723)$ in the second wave $(\mathrm{P}<0.0001)(16)$. Patients from our center were also submitted to the ELSO registry, and we noticed similar baseline characteristics, such as age, BMI, gender, comorbidity, and superinfection before ECMOinitiation (17). A second observation by Broman et al. was that the number of patients on long-term ECMO
(>28 days) increased (16). We also reported longer ECMO runs in patients from the second wave (16 vs. 24.5 days, $\mathrm{P}=0.074)$. In another registry led by the Japan ECMOnet for COVID-19 group, survival rates were approximately $10 \%$ less in patients of the second wave (18). Regarding ECMO duration, the Japanese ECMOnet registry showed increased mortality in patients who underwent ECMO for 16-20 days, and a $65 \%$ mortality risk in patients under ECMO for more than 16 days (18).

Evidence for a direct cause of high mortality rates in 

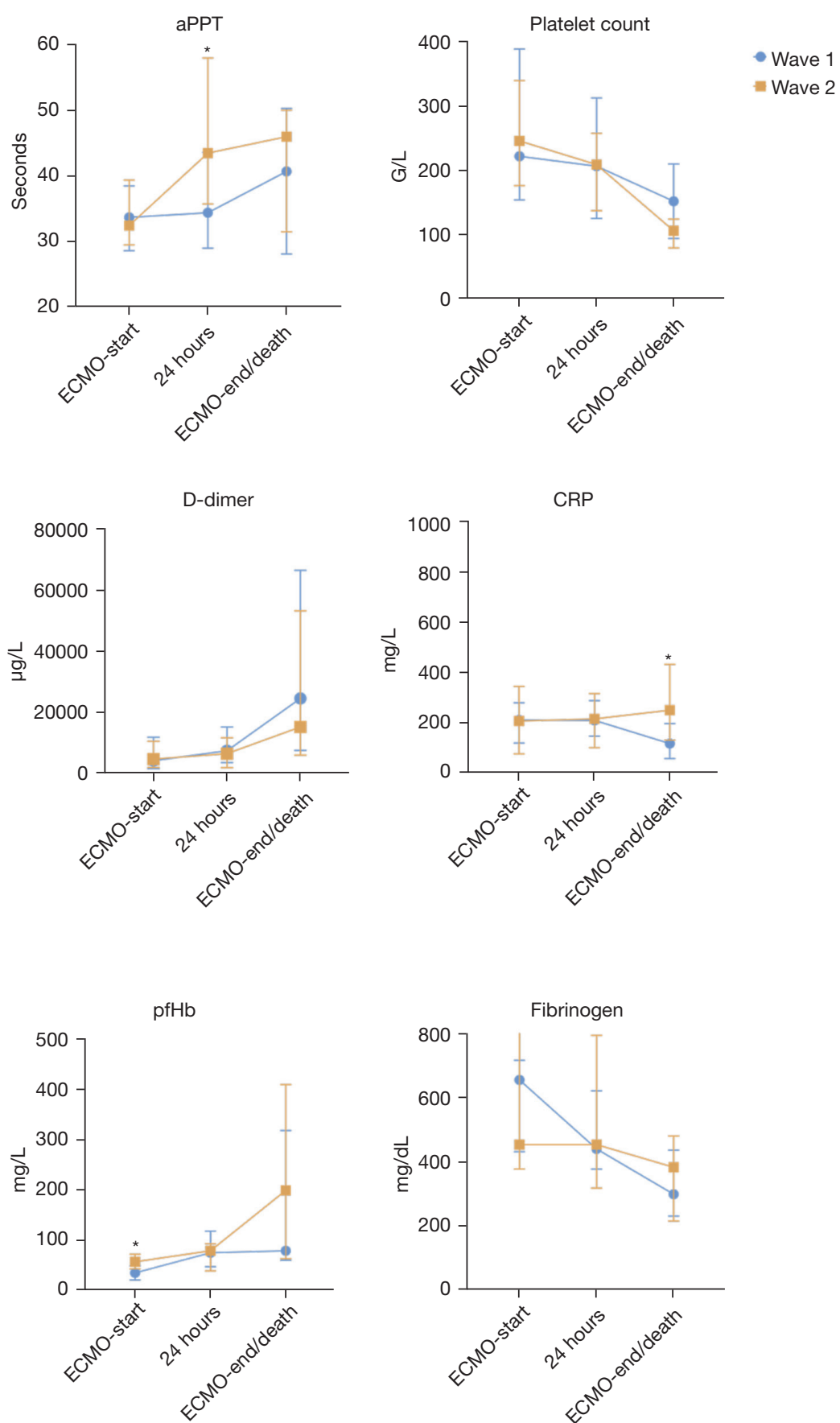

Figure 1 Time course of laboratory parameters in patients from Wave $1(n=19)$ and Wave $2(n=20)$. Measurements are presented as median and interquartile range (IQR). *, P values under 0.05 are considered as significant and tagged with an asterisk. All parameters were measured 1-6 hours before ECMO-initiation. aPTT, partial thromboplastin time; CRP, C-reactive protein; ECMO, extracorporeal membrane oxygenation; pfHb, plasma-free hemoglobin. 


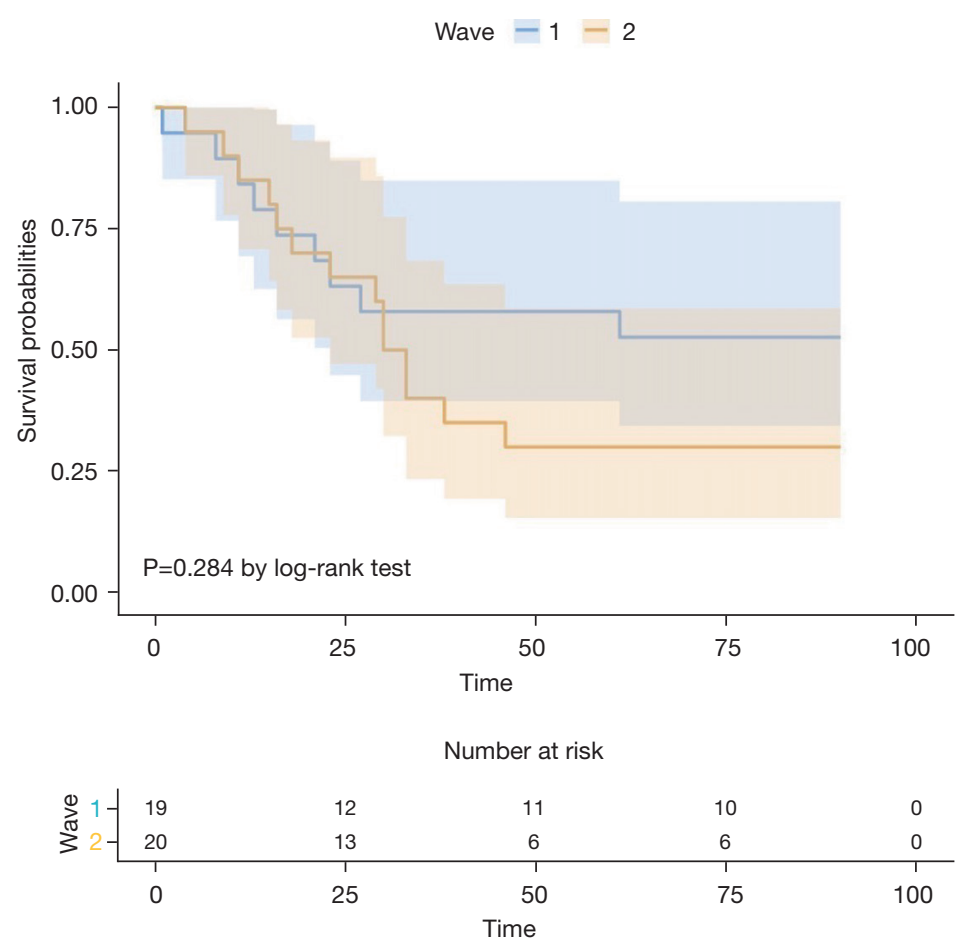

Figure 2 Kaplan-Meier estimates of survival between Wave $1(\mathrm{n}=19)$ and Wave 2 ( $\mathrm{n}=20)$ during the first 90 days after ECMO-initiation. ECMO, extracorporeal membrane oxygenation.

the second wave cannot be provided, however, there are multiple factors that need to be discussed. Patients from the second wave remained for long periods in (ICUs of) referring hospitals and already received steroids and other adjuvants (Table 1). Concurrently, the median time on MV prior ECMO was 9 days in patients of the second wave. MV for $<7$ days is recommended for ECLS in patients with COVID-19 (14); of note, $55 \%$ of patients from the second wave exceeded this limit (Table 1). This was due to late requests for ECMO in our hospital, which have been associated with worse outcomes (19). Specifically, for COVID-19 patients, the Japanese registry and a German analysis reported lower mortality in patients with early onset of ECMO therapy after initiation of MV $(18,20)$. Due to long ICU periods and severe illness, more patients develop acute kidney failure and receive dialysis before the initiation of ECMO. Karagiannidis et al. showed that ECMO-centers in Germany selected more patients with need for dialysis than other countries (20). The prevalence of acute kidney failure was also high in our study, especially during the second wave (Table 3). Looking at the overall COVID-19 population, we found different a different trend between the first and second wave. In Germany, the mortality of mechanically ventilated patients with COVID-19 in ICUs during the first wave was reported to be 53\% (21). Unlike ECMO outcomes, an analysis with patients from the second wave showed that the prognosis of ICU patients, those requiring mechanical ventilation and those not, remained the same (21). An important difference is that compared with in the first wave, $50 \%$ less of all hospitalised patients were admitted to the ICU during the second wave (21). Possible reasons for this difference are clearly defined algorithms for non-invasive treatment strategies, and the early administration of pharmacological treatments, such as dexamethasone. Regarding ECMO patients, a selection bias with patients who did not respond to adjuvant therapies and underwent long hospitalization periods could have affected the outcomes (16). Another important factor is that health care providers experienced higher work load during the second wave, because the absolute number of ICU admissions steadily increased and almost doubled compared with that of the first wave (21). Having said this, we did not experience shortcomings of (ECMO) resources in our center.

A relevant finding of our study were significantly more bleeding events in the second wave (Table 3). A study 
Table 3 Outcomes

\begin{tabular}{|c|c|c|c|c|}
\hline Outcome & Total $(n=39)$ & Wave $1(n=19)$ & Wave $2(n=20)$ & $P$ value \\
\hline ECMO duration (d) & 19 [11-29] & 16 [11-24] & $24.5[15.3-33]$ & 0.074 \\
\hline Thromboembolic events, $\mathrm{n}(\%)^{\dagger \dagger}$ & $14[36]$ & $8[42]$ & $6[30]$ & 0.514 \\
\hline Pulmonary artery embolism & $8[21]$ & $5[26]$ & $3[15]$ & 0.451 \\
\hline Peripheral arterial thrombosis & $2[5]$ & $1[5]$ & $1[5]$ & 1.000 \\
\hline ECMO-circuit thrombus & $3[8]$ & $0[0]$ & $3[15]$ & 0.231 \\
\hline Major bleeding events, $\mathrm{n}(\%)^{\dagger \dagger}$ & 24 [62] & 8 [42] & $16[80]$ & $0.022^{*}$ \\
\hline Endobronchial & 9 [23] & $2[11]$ & 7 [35] & 0.127 \\
\hline Gastrointestinal & $3[8]$ & $1[5]$ & $2[10]$ & 1.000 \\
\hline Cerebral & $3[8]$ & $0[0]$ & 3 [15] & 0.231 \\
\hline Hemothorax & $1[3]$ & $1[5]$ & $0[0]$ & 0.487 \\
\hline Pericardial tamponade & $3[8]$ & $2[11]$ & $1[5]$ & 0.605 \\
\hline Other & $3[8]$ & $0[0]$ & $3[15]$ & 0.231 \\
\hline Acute kidney failure ${ }^{\S}$ & 28 [72] & 13 [68] & 15 [75] & 0.447 \\
\hline \multicolumn{5}{|l|}{ Blood products $^{\dagger \dagger}$} \\
\hline PRBC (units) & 26 [14-46] & 26 [14-38] & 23 [12.8-59] & 0.731 \\
\hline
\end{tabular}

Continuous variables are presented as median and interquartile range [IQR] or $\mathrm{n}(\%) .{ }^{*}, \mathrm{P}$ values under 0.05 are considered as significant and tagged with an asterisk; ${ }^{\dagger}$, discharge to a rehabilitation center, general ward of other hospital or home. We reported death in all other patients; ${ }^{\dagger \dagger}$, during ECMO-therapy; ${ }^{\S}$, all patients with acute kidney failure in stages 2 or 3 by KDIGO guidelines. ECMO, extracorporeal membrane oxygenation; FFP, fresh frozen plasma; LOS, length of stay, PC, platelet cells; PRBC, packed red blood cells.

conducted by Aubron and colleagues investigated bleeding complications in ECMO patients and reported that bleeding was independently associated with worse survival (22). In this study, definition of bleeding was similar to the ISTH classification that we used, and furthermore, bleeding rate was $60 \%$ which was comparably high in our cohort (22). More bleeding complications in the second wave could be explained by longer ECMO runs and more severe sepsis (Table 3). Laboratory measurements (24 h after initiation of ECMO) revealed significantly higher PTT values in patients of the second wave (Table S1). Our approach aimed at a PTT under $60 \mathrm{~s}$, and the median PTT of the patients was 32 (IQR: 30-39) s and 44 (IQR: 36-58) s before and $24 \mathrm{~h}$ after the initiation of ECMO, respectively. As ELSO guidelines recommend PTT values 1.4- or 1.5-fold higher than normal (23), we assume that these values are reasonable. Platelet count was another important laboratory measurement. Compared with patients of the first wave, those of the second wave had lower platelet levels before explantation of ECMO [152 (IQR: 94-210) 
vs. 106 (IQR: 79-124) days, respectively, $\mathrm{P}=0.07]$. Low platelet levels or thrombocytopenia have been associated with bleeding events in patients with COVID-19 receiving ECLS (24) and we aimed for a platelet count $>80 \mathrm{G} / \mathrm{L}$ as recommended in the ELSO guidelines (23). However, a decrease in platelets and thrombocytopenia during ECLS are frequently observed, and the underlying mechanisms of these events are multifactorial (25). Besides that, ECMO runs were longer in patients from the second wave (Table 3). Therefore, low platelet levels before ECMO removal are reasonable. COVID-19 is associated with a hypercoagulable state; hence, guidelines suggested to target anticoagulation at the higher end of normal ECMO parameters (8) during the period of our study. However, we followed the same anticoagulation regimen (described in the Methods section) in all patients. Furthermore, the administration of PRBC units during ECMO therapy was comparable and even higher in patients of the first wave. This may indicate that bleeding in the first wave was less frequent and simultaneously more severe, or the classification of major bleedings established by the ISTH is excessively stringent. Besides that, hemolysis and decreased red cell lifespan is caused by artificial surface and shear stress from the ECMO circuit. Therefore, PRBCs are administered frequently to maintain appropriate Do2:Vo2 ratios and hemoglobin levels. As a result, PRBC units for incidental bleedings cannot stand out in a statistical comparison.

Selection of ARDS patients for ECMO was conducted according to the ELSO guidelines (12). During the study period, we did not change our protocol for ARDS patients as we reported positive results during the first wave. Prone positioning was used in all patients before and on ECMO, however, in some patients we needed to stop because of severe complications. As many studies reported positive results with dexamethasone in mechanically ventilated COVID-19 patients (26), the use of steroids increased from $47 \%$ to $75 \%$ in the second wave (Table 1). Steroids were commonly administered early after hospital admission, and a survival benefit of steroids has been reported in many studies (27). Therefore, the second wave of had more patients who did not respond to steroid therapy and were selected for ECMO therapy. This finding supports the idea of worse outcomes in patients who did not respond to adjuvant therapies (16). Furthermore, some studies suggested that steroids could induce a delayed SARS-CoV-2 clearance from the airway and worsen survival outcomes (28), however, more evidence is needed.

Even though our common approach for ARDS patients did not change, our data revealed some significant differences which need to be discussed. In patients of the first wave, we reported significantly lower $\mathrm{pH}$ prior ECMO (Table 1). In general, this indicates more severe illness and Raasveld et al. reported that COVID-19 non-survivors were more acidotic prior to the initiation of ECMO (29). An explanation for this dubious finding can be acidosis due to a therapeutic modality, which is known to have a protective effect against ventilator-associated lung injury (30) in the absence of right ventricular failure (31). The second epidemic wave was managed with significantly lower PEEP values. Adjustment of appropriate PEEP values was conducted according to lung compliance, and esophageal titration was used in some cases. The difference in PEEP values was small; nevertheless, this suggests that lung compliance, which is associated with mortality in patients with ARDS on ECMO, was less during the second wave (32). We also reported significantly higher BMI values in patients of the second wave, which could have further impaired lung compliance. However, the association between obesity and ECLS mortality remains unclear $(33,34)$. Hemolysis is common in patients receiving ECMO; however, we found significantly higher pfHb levels in patients of the second wave. Omar et al. reported that high pfHb levels $(<50 \mathrm{mg} / \mathrm{dL}, 24 \mathrm{~h}$ after initiation of ECMO) can be used as an independent risk factor for mortality in patients receiving support (35). In the present study, the levels of pfHb were already exceeding this limit prior to the initiation of ECMO therapy. High levels of $\mathrm{pfHb}$ are associated with multiorgan failure $(36,37)$ and may have influenced outcomes. Numerous studies added further knowledge regarding the appropriate utilization of ECMO and found interesting prognostic factors in patients with COVID-19. Old age ( $>65$ years), immunosuppression, need for VA-ECMO, and presence of common comorbidities (hypertension, diabetes, and obesity) are associated with poor ECMO outcomes (14). The present study included only four patients aged $>65$ years, one patient receiving immunosuppressive medication, and one patient who received VA-ECMO. However, comorbidities were present in the majority of patients (Table 1).

The strength of this investigation is that the clinical course before and after the initiation of ECMO is accurately presented and important details are reported. As this was a single-center study, we can ensure that the groups were comparable and received the same treatment. Although our results add further knowledge to the management of patients with COVID-19, the present study has some limitations. One of the main disadvantages is the small 
sample size, which reduced power and increased the margin of error in our study. Furthermore, the probability for false positive findings is high due to a wide range of variables and small number of patients. Multiple comparison correction was considered but common methods, such as Bonferroni correction, would eliminate all significant values of the results. As an early single center analysis, we presented all possible differences with a low threshold. This approach prevented the occurrence of false negatives values which could have been important in the future. Retrospective studies are associated with a potential risk for selection bias, and results are dependent on accurate recordkeeping. For MV parameters (e.g., PEEP) and laboratory values, we only analyzed specific time points which may not reflect longer periods of time and, thus, lead to misconceptions.

\section{Conclusions}

In a single-center study on ECMO-supported patients with COVID-19, we reported an overall survival rate of $41 \%$ in the first year. Similar to various registries, we observed less favorable outcomes during the second wave. Lessons learned from our experience are that direct communication with referring hospitals and early initiation of ECMO remains challenging. We identified two topics for further analysis of patients with COVID-19 receiving ECMO. Studies involving large sample sizes are warranted to identify predictors of mortality, as well as the influence of different SARS-CoV-2 mutations or subtypes on the clinical course and ECMO outcomes.

\section{Acknowledgments}

Funding: None.

\section{Footnote}

Reporting Checklist: The authors have completed the STROBE reporting checklist. Available at https://dx.doi. org/10.21037/jtd-21-971

Data Sharing Statement: Available at https://dx.doi. org/10.21037/jtd-21-971

Peer Review File: Available at https://dx.doi.org/10.21037/ jtd-21-971

Conflicts of Interest: All authors have completed the ICMJE uniform disclosure form (available at https://dx.doi. org/10.21037/jtd-21-971). The authors have no conflicts of interest to declare.

Ethical Statement: The authors are accountable for all aspects of the work in ensuring that questions related to the accuracy or integrity of any part of the work are appropriately investigated and resolved. The study was conducted in accordance with the Declaration of Helsinki (as revised in 2013). The study was approved by the local ethics board of RWTH Uniklinik Aachen (No. 20-085) and individual consent for this retrospective analysis was waived.

Open Access Statement: This is an Open Access article distributed in accordance with the Creative Commons Attribution-NonCommercial-NoDerivs 4.0 International License (CC BY-NC-ND 4.0), which permits the noncommercial replication and distribution of the article with the strict proviso that no changes or edits are made and the original work is properly cited (including links to both the formal publication through the relevant DOI and the license). See: https://creativecommons.org/licenses/by-nc-nd/4.0/.

\section{References}

1. Phua J, Weng L, Ling L, et al. Intensive care management of coronavirus disease 2019 (COVID-19): challenges and recommendations. Lancet Respir Med 2020;8:506-17.

2. Richardson S, Hirsch JS, Narasimhan M, et al. Presenting Characteristics, Comorbidities, and Outcomes Among 5700 Patients Hospitalized With COVID-19 in the New York City Area. JAMA 2020;323:2052-9.

3. Armstrong RA, Kane AD, Kursumovic E, et al. Mortality in patients admitted to intensive care with COVID-19: an updated systematic review and meta-analysis of observational studies. Anaesthesia 2021;76:537-48.

4. Tzotzos SJ, Fischer B, Fischer H, et al. Incidence of ARDS and outcomes in hospitalized patients with COVID-19: a global literature survey. Crit Care 2020;24:516.

5. Marullo AG, Cavarretta E, Biondi Zoccai G, et al. Extracorporeal membrane oxygenation for critically ill patients with coronavirus-associated disease 2019: an updated perspective of the European experience. Minerva Cardioangiol 2020;68:368-72.

6. World Health Organization. Clinical management of COVID-19: interim guidance, 27 May 2020. Geneva: World Health Organization; 2020. Contract No.: WHO/2019-nCoV/clinical/2020.5 
7. Ramanathan K, Antognini D, Combes A, et al. Planning and provision of ECMO services for severe ARDS during the COVID-19 pandemic and other outbreaks of emerging infectious diseases. Lancet Respir Med 2020;8:518-26.

8. Shekar K, Badulak J, Peek G, et al. Extracorporeal Life Support Organization Coronavirus Disease 2019 Interim Guidelines: A Consensus Document from an International Group of Interdisciplinary Extracorporeal Membrane Oxygenation Providers. ASAIO J 2020;66:707-21.

9. Barbaro RP, MacLaren G, Boonstra PS, et al. Extracorporeal membrane oxygenation support in COVID-19: an international cohort study of the Extracorporeal Life Support Organization registry. Lancet 2020;396:1071-8.

10. Ramanathan K, Shekar K, Ling RR, et al. Extracorporeal membrane oxygenation for COVID-19: a systematic review and meta-analysis. Crit Care 2021;25:211.

11. Combes A, Peek GJ, Hajage D, et al. ECMO for severe ARDS: systematic review and individual patient data metaanalysis. Intensive Care Med 2020;46:2048-57.

12. Badulak J, Antonini MV, Stead CM, et al. Extracorporeal Membrane Oxygenation for COVID-19: Updated 2021 Guidelines from the Extracorporeal Life Support Organization. ASAIO J 2021;67:485-95.

13. ARDS Definition Task Force; Ranieri VM, Rubenfeld GD, et al. Acute respiratory distress syndrome: the Berlin Definition. JAMA 2012;307:2526-33.

14. Huang S, Zhao S, Luo H, et al. The role of extracorporeal membrane oxygenation in critically ill patients with COVID-19: a narrative review. BMC Pulm Med 2021;21:116.

15. Schulman S, Kearon C; Subcommittee on Control of Anticoagulation of the Scientific and Standardization Committee of the International Society on Thrombosis and Haemostasis. Definition of major bleeding in clinical investigations of antihemostatic medicinal products in non-surgical patients. J Thromb Haemost 2005;3:692-4.

16. Broman LM, Eksborg S, Coco VL, et al. Extracorporeal membrane oxygenation for COVID-19 during first and second waves. Lancet Respir Med 2021;9:e80-1.

17. COVID-19 Cases on ECMO in the ELSO Registry. Accessed July 28, 2021. Available online: https://www.elso. org/Registry/FullCOVID19RegistryDashboard.aspx

18. Survey of Critically ill COVID-19 patients in Japan, managed by the Japan ECMOnet for COVID-19. Accessed July 28, 2021. Available online: https://crisis. ecmonet.jp

19. Steimer DA, Hernandez O, Mason DP, et al. Timing of
ECMO Initiation Impacts Survival in Influenza-Associated ARDS. Thorac Cardiovasc Surg 2019;67:212-5.

20. Karagiannidis C, Strassmann S, Merten M, et al. High In-Hospital Mortality Rate in Patients with COVID-19 Receiving Extracorporeal Membrane Oxygenation in Germany: A Critical Analysis. Am J Respir Crit Care Med 2021;204:991-4.

21. Karagiannidis C, Windisch W, McAuley DF, et al. Major differences in ICU admissions during the first and second COVID-19 wave in Germany. Lancet Respir Med 2021;9:e47-8.

22. Aubron C, DePuydt J, Belon F, et al. Predictive factors of bleeding events in adults undergoing extracorporeal membrane oxygenation. Ann Intensive Care 2016;6:97.

23. Extracorporeal Life Support Organization. Guidelines for Adult Respiratory Failure. August 2017.

24. Durak K, Kersten A, Grottke O, et al. Thromboembolic and Bleeding Events in COVID-19 Patients receiving Extracorporeal Membrane Oxygenation. Thorac Cardiovasc Surg 2021;69:526-36.

25. Jiritano F, Serraino GF, Ten Cate H, et al. Platelets and extra-corporeal membrane oxygenation in adult patients: a systematic review and meta-analysis. Intensive Care Med 2020;46:1154-69.

26. RECOVERY Collaborative Group; Horby P, Lim WS, et al. Dexamethasone in Hospitalized Patients with Covid-19. N Engl J Med 2021;384:693-704.

27. Ma S, Xu C, Liu S, et al. Efficacy and safety of systematic corticosteroids among severe COVID-19 patients: a systematic review and meta-analysis of randomized controlled trials. Signal Transduct Target Ther 2021;6:83.

28. Liu J, Zhang S, Dong X, et al. Corticosteroid treatment in severe COVID-19 patients with acute respiratory distress syndrome. J Clin Invest 2020;130:6417-28.

29. Raasveld SJ, Delnoij TSR, Broman LM, et al. Extracorporeal Membrane Oxygenation in Patients With COVID-19: An International Multicenter Cohort Study. J Intensive Care Med 2021;36:910-7.

30. Salmon AA, Hotchkiss JR. Hypercapnic acidosis in ARDS: a tolerated side effect or an important therapeutic modality? Crit Care 2007;11:304.

31. Repessé X, Vieillard-Baron A. Hypercapnia during acute respiratory distress syndrome: the tree that hides the forest! J Thorac Dis 2017;9:1420-5.

32. Kim HS, Kim JH, Chung CR, et al. Lung Compliance and Outcomes in Patients With Acute Respiratory Distress Syndrome Receiving ECMO. Ann Thorac Surg 2019;108:176-82. 
33. Blum JM, Stentz MJ. The Known Unknowns of Obesity and Extracorporeal Membrane Oxygenation. Anesth Analg 2020;131:751-3.

34. Galvagno SM Jr, Pelekhaty S, Cornachione CR, et al. Does Weight Matter? Outcomes in Adult Patients on Venovenous Extracorporeal Membrane Oxygenation When Stratified by Obesity Class. Anesth Analg 2020;131:754-61.

35. Omar HR, Mirsaeidi M, Socias S, et al. Plasma Free Hemoglobin Is an Independent Predictor of Mortality

Cite this article as: Durak K, Zayat R, Grottke O, Dreher M, Autschbach R, Marx G, Marx N, Spillner J, Kalverkamp $\mathrm{S}$, Kersten A. Extracorporeal membrane oxygenation in patients with COVID-19: 1-year experience. J Thorac Dis 2021;13(10):5911-5924. doi: 10.21037/jtd-21-971 among Patients on Extracorporeal Membrane Oxygenation Support. PLoS One 2015;10:e0124034.

36. Vermeulen Windsant IC, Hanssen SJ, Buurman WA, et al. Cardiovascular surgery and organ damage: time to reconsider the role of hemolysis. J Thorac Cardiovasc Surg 2011;142:1-11.

37. Rother RP, Bell L, Hillmen P, et al. The clinical sequelae of intravascular hemolysis and extracellular plasma hemoglobin: a novel mechanism of human disease. JAMA 2005;293:1653-62. 
Supplementary

Table S1 Time course of laboratory parameters

\begin{tabular}{|c|c|c|c|c|}
\hline Parameter & Total $(n=39)$ & Wave $1(n=19)$ & Wave $2(n=20)$ & $P$ value \\
\hline \multicolumn{5}{|l|}{$\mathrm{Hb}(\mathrm{g} / \mathrm{dL})$} \\
\hline Pre-ECMO & $9.8(9-11.4)$ & $9.8(8.7-10.5)$ & $9.8(9.15-11.6)$ & 0.531 \\
\hline $24 \mathrm{~h}$ after ECMO-initiation & $9.7(8.5-10.4)$ & $9.6(8.7-10.7)$ & $9.7(8-10.2)$ & 0.687 \\
\hline Pre-Explantation & $9.7(9-10.5)$ & $9.7(9.2-10.5)$ & $9.9(9-10.5)$ & 0.685 \\
\hline Pre-ECMO & $13(10.1-19.1)$ & $14.3(10.1-21.9)$ & $12.15(9.8-16.3)$ & 0.214 \\
\hline $24 \mathrm{~h}$ after ECMO-initiation & $11.7(8.6-15.6)$ & $13(9.4-16.8)$ & $11(8.1-14.6)$ & 0.283 \\
\hline Pre-Explantation & $13(8.6-18.5)$ & $16(8.9-20)$ & $11.15(6.7-16)$ & 0.178 \\
\hline \multicolumn{5}{|l|}{ Platelet (G/L) } \\
\hline Pre-Explantation & $115(81-165)$ & $152(94-210)$ & $106(79-124)$ & 0.07 \\
\hline \multicolumn{5}{|l|}{ PCT (percentage) } \\
\hline Pre-ECMO & $2.2(0.6-8.3)$ & $4.5(0.6-6.5)$ & $1.5(0.6-9.1)$ & 0.813 \\
\hline $24 \mathrm{~h}$ after ECMO-initiation & $2.4(1-6.5)$ & $3.5(1.2-7.3)$ & $1.7(0.8-4.1)$ & 0.184 \\
\hline Pre-Explantation & $6(1.5-11.8)$ & $3(0.6-10.2)$ & $7.8(1.6-28.5)$ & 0.284 \\
\hline \multicolumn{5}{|l|}{ aPTT (s) } \\
\hline Pre-ECMO & 33 (29-39) & 34 (29-39) & $32(30-39)$ & 0.989 \\
\hline $24 \mathrm{~h}$ after ECMO-initiation & $38(30-52)$ & $34(29-44)$ & $44(36-58)$ & $0.038^{*}$ \\
\hline \multicolumn{5}{|l|}{ Fibrinogen (mg/dL) } \\
\hline Pre-ECMO & $466(409-717)$ & $656(432-717)$ & $455(379-853)$ & 0.607 \\
\hline $24 \mathrm{~h}$ after ECMO-initiation & $445(349-652)$ & 441 (378-622) & 455 (319-795) & 0.934 \\
\hline Pre-Explantation & $365(239-443)$ & $300(232-437)$ & $384(217-482)$ & 0.538 \\
\hline \multicolumn{5}{|l|}{ D-dimer ( $\mu \mathrm{g} / \mathrm{dL})$} \\
\hline Pre-ECMO & 4547 (1876-11006) & 4345 (1745-12046) & 4869 (2117-10698) & 0.967 \\
\hline $24 \mathrm{~h}$ after ECMO-initiation & 6773 (2813-14702) & 7591 (3716-15359) & 6662 (2079-11847) & 0.351 \\
\hline Pre-Explantation & $16894(7523-56315)$ & 24689 (7734-66545) & $15361(6174-53328)$ & 0.499 \\
\hline \multicolumn{5}{|l|}{ ATIII (\%) } \\
\hline Pre-ECMO & $66(55-77)$ & $65(54-76)$ & $67(56-88)$ & 0.328 \\
\hline $24 \mathrm{~h}$ after ECMO-initiation & $66(48-81)$ & $48(39-75)$ & 71 (62-99) & $0.008^{\star}$ \\
\hline Pre-Explantation & $82(71-100)$ & $81(69-93)$ & $98(69-112)$ & 0.362 \\
\hline
\end{tabular}

Table S1 (continued) 
Table S1 (continued)

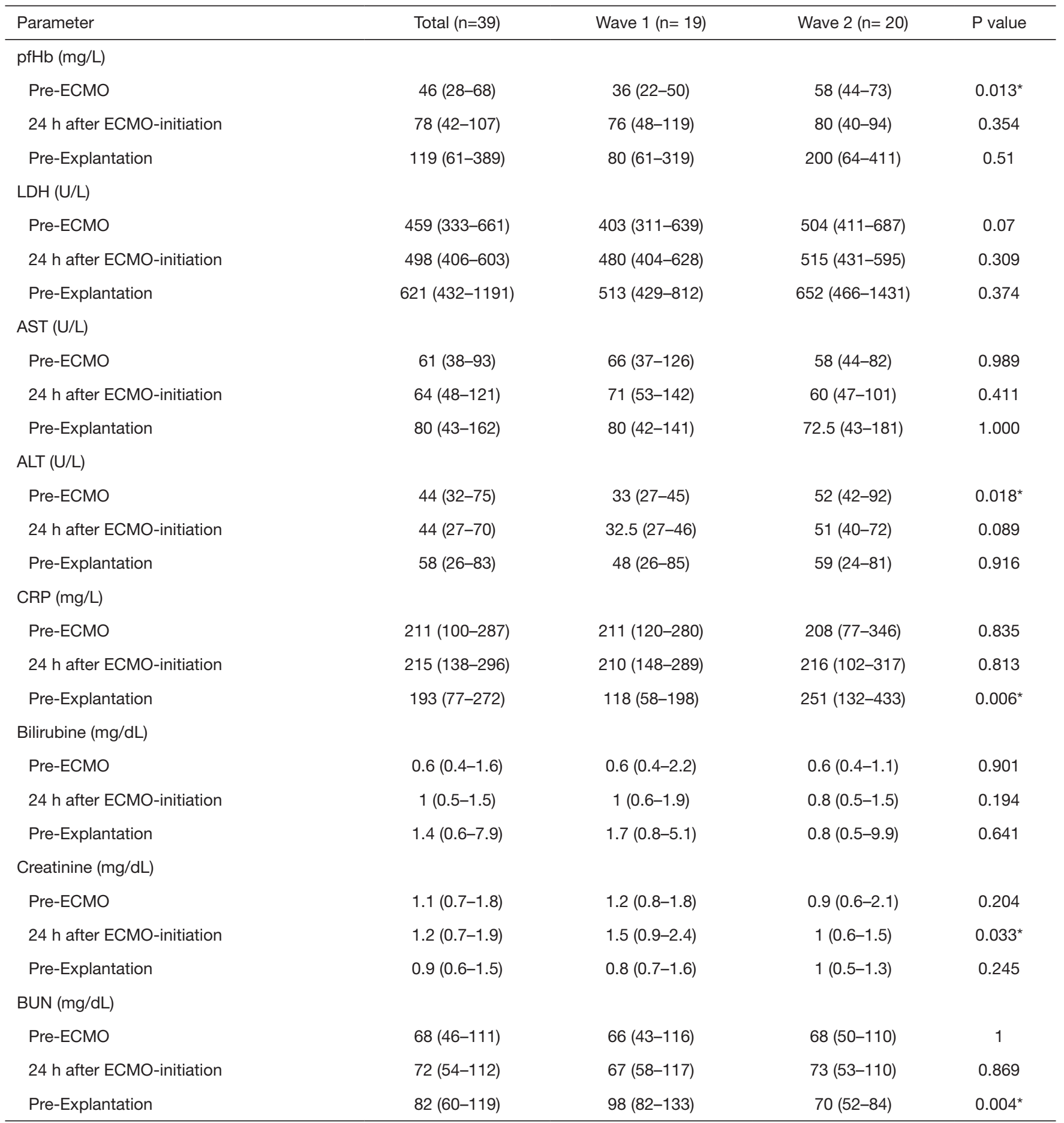

Continuous variables are presented as median and interquartile range (IQR) unless indicated as percentage. *, P values under 0.05 are considered as significant and tagged with an asterisk. All parameters were measured 1-6 hours before ECMO-initiation. ALT, alanine transaminase; AST, aspartate transaminase; ATIII, Antithrombin III, aPTT, partial thromboplastin time; BUN, blood urea nitrogen; CRP, C-reactive protein; ECMO, extracorporeal membrane oxygenation; Hb, Hemoglobin; $\mathrm{LDH}$, lactate dehydrogenase; PCT, procalcitonin; pfHb, plasma-free hemoglobin; WBC, white blood cells. 